\title{
Impact of Deep Brain Stimulation Therapy on Autonomic Disturbances and Related Symptoms of Parkinson's Disease
}

Xiang Hong Wang ${ }^{1,2}$, Laura Sperry ${ }^{1}$, John Olichney ${ }^{1,3}$, Sarah Tomaszewski Farias ${ }^{1}$, Kiarash Shahlaie ${ }^{1,3,4}$, Norika Malhado-Chang ${ }^{1}$, Vicki Wheelock ${ }^{1}$ and Lin $^{\text {. }}$ Zhang $^{1^{*}}$

${ }^{1}$ Department of Neurology, University of California Davis, China

${ }^{2}$ Department of Neurology, Dalian Municipal Central Hospital, China

${ }^{3}$ Center for Neuroscience, University of California Davis, China

${ }^{4}$ Department of Neurological Surgery, University of California Davis, China

*Corresponding author: Lin Zhang, Department of Neurology, University of California Davis, 4800 Y Street, Sacramento, CA 95817, USA, Tel: 916-734-6284; Fax: 916-734-6525; E-mail: Lin.Zhang@ucdmc.ucdavis.edu

Rec date: Sep 22, 2014, Acc date: Nov 11, 2014, Pub date: Nov 20, 2014

Copyright: ( 2015 Wang $\mathrm{XH}$, et al. This is an open-access article distributed under the terms of the Creative Commons Attribution License, which permits unrestricted use, distribution, and reproduction in any medium, provided the original author and source are credited.

\begin{abstract}
Deep brain stimulation (DBS) is an effective treatment option for patients with Parkinson's disease (PD), essential tremor and certain types of dystonia. DBS surgery is typically offered to patients that have diminishing benefits from dopamine replacement therapy with prominent motor fluctuations. Recent research has also shown that DBS can have a significant impact on non-motor symptoms (NMSs), including influencing autonomic and related symptoms. In this editorial, we will evaluate these publications and discuss the often positive impact of DBS on autonomic symptoms, weight changes, sleep disturbances and sensory function.
\end{abstract}

Keywords: Deep brain stimulation; Parkinson's disease; Autonomic function; Globus pallidus interna; Subthalamic nucleus

\section{Abbreviations: \\ DBS: Deep Brain Stimulation; STN: Subthalamic Nucleus; GPi: Globus Pallidus Interna; PD: Parkinson's Disease; NMSs: Non-motor Symptoms; Vim: Ventral Intermediate Thalamic Nucleus; PLM: Periodic Leg Movements; RLS: Restless Legs Syndrome; REM: Rapid- Eye Movement Sleep; DT: Detection Threshold; IT: Identification Threshold; DRT: Dopaminergic Replacement Therapy}

\section{Introduction}

During the past 20 years, DBS has become an important therapeutic option for PD patients, especially for those with motor complications of dopaminergic treatment, such as motor fluctuations and dyskinesias. It has been shown that DBS treatment significantly improves tremor, rigidity, and bradykinesia. As a result, oral medication needs are usually reduced following STN DBS surgery $[1,2]$. Aside from motor symptoms, majority of patients with PD experience significant NMSs. The influence of NMSs on quality of life can be as prominent as motor dysfunction and complications of medications, especially for those patients with advanced stages of PD [3]. Recently, Klingelhoefer and colleagues reviewed the impact of deep brain stimulation on NMSs in PD, focusing on neuropsychiatric symptoms [1]. They concluded that STN and GPi DBS is a safe procedure with respect to cognitive morbidity over short- and long term follow-up in carefully selected patients.

Dysfunction of the autonomic nervous system is common in PD, and it increase with progression of disease, causing a major impact on quality of life [4]. Not only central system is thought to be due to autonomic dysfunction $[5,6]$ but also peripheral sympathetic denervation are demonstrated involving it $[7,8]$. As basal ganglia is connected to areas involving in regulation of the autonomic nervous system [9] STN-DBS may affect autonomic nervous system functions. Some studies have indicated that some autonomic symptoms may improve following STN DBS. In this review, a focused literature search was performed to review the effects of DBS treatment on dysautonomia, sensation, sleep, and weight.

\section{Thermoregulation and Sweating Disturbances}

Thermoregulation is impaired in patients with PD and sweating abnormalities can be troublesome [10]. Abnormal sensations of heat or cold, impaired sweating responses, and hypothermia can all occur [10]. Severe drenching sweats occur commonly as an end-of-dose "off" phenomenon in patients with advanced disease, which may be satisfactorily controlled with adequate dopamine replacement therapy [11].

STN-DBS seems to improve disturbances in temperature sensations in patients with PD [12]. Cold and warm sense thresholds of patients were lower during the DBS-on mode when compared with the DBSoff mode [12]. Drenching sweats and akathisia showed a remarkably good response to chronic STN stimulation [13]. Imaging studies with reconstruction indicated that stimulation of, or spread of stimulation from, the caudal medial aspect of the STN and/or the caudal aspect of the ventral thalamus/zona incerta may be responsible for alleviating drenching sweats [14].

\section{Urinary Symptoms}

Urinary symptoms are among the most frequent non-motor symptoms in patients with PD. They occur in $38-71 \%$ of patients with $\mathrm{PD}$, typically manifesting as nocturia, urgency, and frequency. The mechanisms of these symptoms may be earlier perception of bladder 
sensation resulting in detrusor overactivity [15]. STN DBS has been shown to have variable results on urinary symptoms. Some studies suggest improvement in urinary symptomatology after STN DBS [16-18] with improvements in detrusor hyperreflexia [17] and increased bladder capacity [18]. A study on regional cerebral blood flow measured by PET showed that STN-DBS can modulate neural activity in the thalamus and insular cortex by periaqueductal grey activity, an effect that results in enhancement of afferent urinary bladder information processing [16]. Fritsche and colleagues reported two patients that developed acute urinary retention following DBS [19]. The phenomenon may be due to suboptimal positioning of the electrodes [19].

\section{Orthostatic Hypotension}

Orthostatic hypotension is a common problem in patients with advanced PD. Levodopa and most anti-parkinsonian medications may exacerbate orthostatic hypotension [20,21]. STN-DBS may improve orthostatic hypotenion by increasing heart rate, improving baroreceptor sensitivity, and increasing peripheral vasoconstriction $[22,23]$. Targeted electric DBS in STN can enhance sympathetic regulation; the autonomic response may be due to electrical signals being distributed to limbic components of the STN or descending sympathetic pathways in the zona incerta [24]. GPi stimulation showed no change in cardiovascular parameters $[25,26]$.

\section{Gastrointestinal Symptoms}

Gastrointestinal dysfunction such as dysphagia, reflux and constipation is common in patients with advanced PD. In fact, aspiration pneumonia secondary to dysphagia is a leading cause of death in PD [27]. The gastrointestinal dysfunction likely results from degeneration of extranigral lesions related to neural control of gastrointestinal tract function, such as cells in the dorsal vagal nucleus and the intramural intestinal plexus [28]. The ideal strategy for the management of gastrointestinal dysfunction remains uncertain.

Bilateral STN-DBS can improve gastric emptying [29], salivation swallowing, and constipation [30]. Lengerer and colleagues reported DBS has no clinically significant effect on deglutition [31], but a study using video fluoroscopy found improvements in some aspects of pharyngeal swallowing following STN-DBS [32]. It is possible that STN-DBS modulates thalamocortical or brainstem targets to overcome the bradykinesia and hypokinesia associated with pharyngeal muscles, improving the pharyngeal stage. Stimulation of certain areas of basal ganglia and/or the entire basal ganglia circuits may contribute to selecting appropriate swallow motor plans based on propioceptive feedback, and adapting these plans in the context of environment (what is being swallowed) [32]. Recently, Troche MS and colleagues reviewed 9 studies specifically addressing the effects of DBS on swallowing, concluding that none of these studies demonstrated clinically significant effects of DBS on swallowing function. There is no data to suggest that STN or GPi have differential effects on swallowing function [33].

\section{Sexual Dysfunction}

In general, studies on sexual dysfunction in PD patients have been relatively sparse. Dopamine agonists and levodopa can increase sexual wellbeing [34] Age, severity of disease, and depression seem to be the most important predictors of sexual wellbeing in PD [35]. Castelli and colleagues conducted questionnaires in 31 patients with $\mathrm{PD}$ investigating the impact of DBS on sexual function. They found a small but significant improvement in sexual functioning in male patients with PD 1-year after bilaterally DBS surgery, particularly in those less than 60 years of age. No difference in sexual satisfaction was found in the women. They also found that changes in sexual satisfaction after surgery had no correlation with improvement in depression, anxiety, or motor function [36]. These sexual disturbances may be due to the change in activity of medial preoptic anterior hypothalamic nuclei and DBS stimulation of projections to the nucleus accumbens, both responsible for sexual functions [37].

\section{Sleep Disturbance}

Sleep disturbances in patients with PD are multifactorial. While degeneration of dopaminergic and nondopaminergic neurons in the brainstem cause specific sleep disorders, parkinsonian motor dysfunction, dyskinesias, pain, nocturia, and dopaminergic and nondopaminergic medications may all contribute to sleep disturbances [10]. Recent studies have suggested that STN-DBS improves subjective and objective measures of sleep in patients with PD. Bilateral STN-DBS decreased awake state after sleep onset, improved nocturnal mobility, RLS, nocturia, and increased continuous sleep time and sleep efficiency [38-42]. Polysomnography showed that STN stimulation increased the durations of deep slow wave sleep and REM sleep, but the proportion of time spent in each sleep stage was not significantly different. When stimulation was absent, sleep disturbances were similar to those observed before surgery [43]. These polysomnographic changes suggest a direct effect of STN stimulation on the sleep regulatory center. However, in most studies, excessive daytime somnolence, periodic limb movements of sleep, and REM sleep behavior, did not improve after bilateral STN-DBS $[40,44]$. As proposed by Iranzo and colleagues [45], the persistence of REM behavior disorder after surgery suggests that electrical inactivation of the STN does not restore the pedunculopontine activity which promotes muscle atonia during REM sleep [46], whereas the persistence or increase of PLM might reflect the reduction of postoperative dopaminergic treatment [45]. Kedia and colleague reported new problematic symptoms of RLS could be reversed by dopaminergic drugs [47].

Gpi-DBS has been reported to improve sleep quality [48] as well as subjective daytime sleepiness in individuals who did not have their anti-Parkinsonian medications reduced. It is not known if dopaminergic medicines or GPi-DBS itself is involved in the positive effects on sleep [49]. Stimulation of Vim did not modify sleep quality or architecture [50].

\section{Weight Loss}

Weight loss in patients with PD is associated with a loss of fat mass years before a formal diagnosis is made [51]. A variety of factors have been implicated in weight loss, including increased metabolic demand from motor symptoms, decreased caloric intake from motor disability, a side effect of medication [52], and secondary dysfunction of central energy homeostasis.

Postoperative gain in body weight following bilateral STN-DBS was found in two studies $[53,54]$. Bodyweight increases most rapidly within the first 3 months after surgery, and weight gain slowly increases in the long term [54]. The quick initial weight gain might be explained by the transient euphoria in the immediate postoperative phase, which is often associated with increased appetite [55], and the 
reduction of energy expenditure (reduced dyskinesia, rigidity, and tremor). Postoperative eating behavior disorders (so-called emotional eating and snacking) are frequently noted in apathetic patients, which is also described in patients with depression [56]. Weight variation in PD before and after DBS-STN is influenced by noradrenergic interaction between the locus coeruleus, the STN, and the hypothalamic nucleus. The locus coeruleus plays an important role in regulating energy metabolism through its noradrenergic connections with the hypothalamus. Noradrenergic degeneration is an important hallmark in PD because of neuronal loss in the locus coeruleus [57].

In a comparative study, weight gain was more frequent and more severe in patients who underwent subthalamic surgery than in patients who had pallidal surgery. There were no significant changes in food intake, either qualitatively or quantitatively, in the two groups [58]. It was concluded that an additional effect of DBS-STN on the homeostatic control centers may have contributed to the difference in weight gain between the two targets. Vim stimulation seems not to result in weight gain in patients with essential tremor, but there is inadequate evidence that this may occur in PD [59].

\section{Pain}

Approximately $70 \%$ to $80 \%$ of patients with PD suffer from chronic pain syndromes over the course of their disease [60]. Pain severely impairs quality of life, and in the setting of PD different types of painful symptoms may arise. Since pain mechanisms are not clearly understood, the current therapeutic strategy is mainly symptomatic.

Levodopa has been shown to improve sensory symptoms by increasing pain threshold [61]. Similarly, clinical studies have demonstrated that STN-DBS may reduce pain intensity and lengthen pain-free intervals $[62,63]$. In patients with $\mathrm{PD}$, dystonic pain and central pain significantly improve following STN-DBS surgery, with more modest improvements in radicular/neurotic and musculoskeletal pain [62]. Pain due to camptocormia only shows mild improvement with STN or GPi stimulation [64]. Post-DBS follow-up evaluations showed the mean pain score at to be lower than that at baseline and development of new pain occurred at a similar rate as that of the general aging population [65]. This is particularly significant since central pain generally worsens with progression of PD [66].

The mechanisms by which STN-DBS improves pain in PD remain unclear. Since musculoskeletal pain and dystonic pain are typically related to increased muscle tone or rigidity, it is possible that STNDBS provides pain relief by alleviation of rigidity. It is also possible that improvements in depressive symptoms after DBS contribute to improved pain control. One potential mechanism for pain relief following STN-DBS may be the modulation of the lateral discriminative pain system, which is impaired in PD patients with neuropathic pain [67]. Stimulation of the posteroventral lateral GPi has also been suggested to improve pain and dysaesthesia in advanced PD up to $74 \%$; the improvement in such symptoms was sustained at the one year follow up [68]. The result is similar to reports of pallidotomy, suggesting that the basal ganglia play a critical role in modulating pain [69].

\section{Dysosmia}

Olfactory dysfunction is an early symptom in PD, often presenting before the motor symptoms [70]. DRT does not improve olfactory function [71]. Patients treated with bilateral STN-DBS showed no significant alterations in odor DT scores in the stimulator-on and off conditions, whereas odor IT scores were significantly improved in the stimulation-on relative to the stimulation off condition[72,73], which may indicate that DBS has a positive effect on the cognitive processing of olfactory information in patients with PD.

It remains unclear why the odor IT improved but the odor DT did not after DBS treatment. It is possible that odor DT is a low-level marker of olfactory function and is related to the degree of pathological impairment of the olfactory bulb and anterior olfactory nucleus. [74] Because these structures are damaged in early stages of PD [75], stimulation may not be able to improve the function of these areas. In contrast, olfactory identification is not only related to higherorder olfactory center operations but also to higher-level cognitive functioning [74]. These cortical regions relevant to olfactory identification are only damaged in advanced PD. A previous study demonstrated that when PD patients lose all olfactory functioning, and olfactory DT increases maximally, DBS no longer improves olfactory dysfunction [73]. Fibers involved in the production, integration, and transmission of olfactory information are located in numerous cortical and subcortical regions sharing vast connections with the STN [73], and striatal dopamine metabolism is related to olfactory identification $[76,77]$, which indicates that STN-DBS may regulate abnormal excitability to improve olfactory identification [78]. The prefrontal lobe and cingulate gyrus are closely related to mood and are easily influenced by odor [79]. Since DBS may improve somatic and psychiatric symptoms, it may also increase the olfactory sensitivity of PD patients.

No data are available on dysosmia in PD patients following GPiand Vim-DBS.

\section{Conclusions}

Most of the current literature on the effects of DBS on autonomic nervous system dysfunction is based on using STN as the target, with limited data on GPi and almost no evidence from Vim for PD. We summarized the impact of these three commonly used DBS targets on NMSs of PD patients in Table 1. It shows that STN-DBS may be a safe procedure with regard to pre-existing dysautonomia. In fact, STNDBS may even have beneficial effects on non-motor symptoms such as pain, sleep, weight, gastrointestinal disturbance, sweating, orthostatic hypotension, anosmia, bladder overactivity, and sexual dysfunction. In conclusion, improvements in these non-motor symptoms may significantly improve quality of life of $\mathrm{PD}$ patients beyond improvements resulting from motor benefits alone. GPi DBS may produce similar results, but further clinical research is needed. As the motor effects of STN-DBS and GPi DBS are similar [48], it is possible that NMSs may determine the target of choice in the future.

\begin{tabular}{|l|l|l|l|}
\hline & STN & GPi & Vim \\
\hline Verbal fluency & Declined & Possibly declined & Unknown \\
\hline Pain & Improved & Improved & Adverse events \\
\hline Dysosmia & Improved & Unknown & Unknown \\
\hline Sleep disturbance & $\begin{array}{l}\text { Some aspects } \\
\text { Improved, some } \\
\text { aspects } \\
\text { unchanged }\end{array}$ & Improved & Unchanged \\
\hline Weight loss & Gain & Gain less & Possible none \\
\hline
\end{tabular}




\begin{tabular}{|l|l|l|l|}
\hline Dysphagia & $\begin{array}{l}\text { Uncertain, possibly } \\
\text { improved }\end{array}$ & Uncertain & Unknown \\
\hline $\begin{array}{l}\text { Cardiovascular } \\
\text { disturbance }\end{array}$ & Improved & Unchanged & Unknown \\
\hline Urinary symptoms & Improved & Unknown & Unknown \\
\hline Thermoregulation & Improved & Unknown & Unknown \\
\hline Drenching sweats & Improved & Unknown & Unknown \\
\hline $\begin{array}{l}\text { Sexual } \\
\text { dysfunction }\end{array}$ & Man improved & Unknown & \\
\hline
\end{tabular}

Table 1: Synopsis of the impact of the most commonly used DBS targets on NMSs in PD patients

\section{References}

1. Klingelhoefer L, Samuel M, Chaudhuri KR, Ashkan K (2014) An update of the impact of deep brain stimulation on non motor symptoms in Parkinson's disease. J Parkinsons Dis 4: 289-300.

2. Deuschl G, Paschen S, Witt K (2013) Clinical outcome of deep brain stimulation for Parkinson's disease. Handb Clin Neurol 116: 107-128.

3. Szewczyk-Krolikowski K, Tomlinson P, Nithi K, Wade-Martins R, Talbot $\mathrm{K}$, et al. (2014) The influence of age and gender on motor and non-motor features of early Parkinson's disease: initial findings from the Oxford Parkinson Disease Center (OPDC) discovery cohort. Parkinsonism Relat Disord 20: 99-105.

4. Jost WH (2003) Autonomic dysfunctions in idiopathic Parkinson's disease. J Neurol 250 Suppl 1: I28-30.

5. Braak H, Ghebremedhin E, Rüb U, Bratzke H, Del Tredici K (2004) Stages in the development of Parkinson's disease-related pathology. Cell Tissue Res 318: 121-134.

6. Benarroch EE, Schmeichel AM, Parisi JE (2000) Involvement of the ventrolateral medulla in parkinsonism with autonomic failure Neurology 54: 963-968.

7. Orimo S, Oka T, Miura H, Tsuchiya K, Mori F, et al. (2002) Sympathetic cardiac denervation in Parkinson's disease and pure autonomic failure but not in multiple system atrophy. J Neurol Neurosurg Psychiatry 73: 776-777.

8. Minguez-Castellanos A, Chamorro CE, Escamilla-Sevilla F, OrtegaMoreno A, Rebollo AC, et al. (2007) Do alpha-synuclein aggregates in autonomic plexuses predate Lewy body disorders?: a cohort study. Neurology 68: 2012-2018.

9. Lovick T (2014) Deep brain stimulation and autonomic control. Exp Physiol 99: 320-325.

10. Olanow CW, Stern MB, Sethi K (2009) The scientific and clinical basis for the treatment of Parkinson disease (2009). Neurology 72: S1-136.

11. Pursiainen V, Haapaniemi TH, Korpelainen JT, Sotaniemi KA, Myllylä VV (2007) Sweating in Parkinsonian patients with wearing-off. Mov Disord 22: 828-832.

12. Maruo T, Saitoh Y, Hosomi K, Kishima H, Shimokawa T, et al. (2011) Deep brain stimulation of the subthalamic nucleus improves temperature sensation in patients with Parkinson's disease. Pain 152: 860-865.

13. Witjas T, Kaphan E, Régis J, Jouve E, Chérif AA, et al. (2007) Effects of chronic subthalamic stimulation on nonmotor fluctuations in Parkinson's disease. Mov Disord 22: 1729-1734.

14. Sanghera MK, Ward C, Stewart RM, Mewes K, Simpson RK, et al. (2009) Alleviation of drenching sweats following subthalamic deep brain stimulation in a patient with Parkinson's disease--a case report. J Neurol Sci 285: 246-249.

15. Winge K, Fowler CJ (2006) Bladder dysfunction in Parkinsonism: mechanisms, prevalence, symptoms, and management. Mov Disord 21: 737-745.
16. Herzog J, Weiss PH, Assmus A, Wefer B, Seif C, et al. (2008) Improved sensory gating of urinary bladder afferents in Parkinson's disease following subthalamic stimulation. Brain 131: 132-145.

17. Winge K, Nielsen KK, Stimpel H, Lokkegaard A, Jensen SR, et al. (2007) Lower urinary tract symptoms and bladder control in advanced Parkinson's disease: effects of deep brain stimulation in the subthalamic nucleus. Mov Disord 22: 220-225.

18. Herzog J, Weiss PH, Assmus A, Wefer B, Seif C, et al. (2006) Subthalamic stimulation modulates cortical control of urinary bladder in Parkinson's disease. Brain 129: 3366-3375.

19. Fritsche HM, Ganzer R, Schlaier J, Wieland WF, Brawanski A, et al. (2009) Acute urinary retention in two patients after subthalamic nucleus deep brain stimulation (STN-DBS) for the treatment of advanced Parkinson's disease. Mov Disord 24: 1553-1554.

20. Bhattacharya KF, Nouri S, Olanow CW, Yahr MD, Kaufmann H (2003) Selegiline in the treatment of Parkinson's disease: its impact on orthostatic hypotension. Parkinsonism Relat Disord 9: 221-224.

21. Lyytinen J, Sovijärvi A, Kaakkola S, Gordin A, Teräväinen H (2001) The effect of catechol-O-methyltransferase inhibition with entacapone on cardiovascular autonomic responses in L-Dopa-treated patients with Parkinson's disease. Clin Neuropharmacol 24: 50-57.

22. Stemper B, Beric A, Welsch G, Haendl T, Sterio D, et al. (2006) Deep brain stimulation improves orthostatic regulation of patients with Parkinson disease. Neurology 67: 1781-1785.

23. Priori A, Cinnante C, Genitrini S, Pesenti A, Tortora G, et al. (2001) Non-motor effects of deep brain stimulation of the subthalamic nucleus in Parkinson's disease: preliminary physiological results. Neurol Sci 22: 85-86.

24. Liu KD, Shan DE, Kuo TB, Yang CC (2013) The effects of bilateral stimulation of the subthalamic nucleus on heart rate variability in patients with Parkinson's disease. J Neurol 260: 1714-1723.

25. Kaufmann H, Bhattacharya KF, Voustianiouk A, Gracies JM (2002) Stimulation of the subthalamic nucleus increases heart rate in patients with Parkinson disease. Neurology 59: 1657-1658.

26. Thornton JM, Aziz T, Schlugman D, Paterson DJ (2002) Electrical stimulation of the midbrain increases heart rate and arterial blood pressure in awake humans. J Physiol 539: 615-621.

27. Fernandez HH, Lapane KL (2002) Predictors of mortality among nursing home residents with a diagnosis of Parkinson's disease. Med Sci Monit 8: CR241-246.

28. Jost WH (2010) Gastrointestinal dysfunction in Parkinson's Disease. J Neurol Sci 289: 69-73.

29. Arai E, Arai M, Uchiyama T, Higuchi Y, Aoyagi K, et al. (2012) Subthalamic deep brain stimulation can improve gastric emptying in Parkinson's disease. Brain 135: 1478-1485.

30. Zibetti M, Torre E, Cinquepalmi A, Rosso M, Ducati A, et al. (2007) Motor and nonmotor symptom follow-up in parkinsonian patients after deep brain stimulation of the subthalamic nucleus. Eur Neurol 58: 218-223.

31. Lengerer S, Kipping J, Rommel N, Weiss D, Breit S, et al. (2012) Deepbrain-stimulation does not impair deglutition in Parkinson's disease. Parkinsonism Relat Disord 18: 847-853.

32. Ciucci MR, Barkmeier-Kraemer JM, Sherman SJ (2008) Subthalamic nucleus deep brain stimulation improves deglutition in Parkinson's disease. Mov Disord 23: 676-683.

33. Troche MS, Brandimore AE, Foote KD, Okun MS (2013) Swallowing and deep brain stimulation in Parkinson's disease: a systematic review. Parkinsonism Relat Disord 19: 783-788.

34. Uitti RJ, Tanner CM, Rajput AH, Goetz CG, Klawans HL, et al. (1989) Hypersexuality with antiparkinsonian therapy. Clin Neuropharmacol 12: 375-383.

35. Lipe H, Longstreth WT Jr, Bird TD, Linde M (1990) Sexual function in married men with Parkinson's disease compared to married men with arthritis. Neurology 40: 1347-1349. 
36. Castelli L, Perozzo P, Genesia ML, Torre E, Pesare M, et al. (2004) Sexua well being in parkinsonian patients after deep brain stimulation of the subthalamic nucleus. J Neurol Neurosurg Psychiatry 75: 1260-1264.

37. Usunoff KG, Schmitt O, Itzev DE, Haas SJ, Lazarov NE, et al. (2009) Efferent projections of the anterior and posterodorsal regions of the medial nucleus of the amygdala in the mouse. Cells Tissues Organs 190: 256-285.

38. Gallagher DA, Lees AJ, Schrag A (2010) What are the most important nonmotor symptoms in patients with Parkinson's disease and are we missing them? Mov Disord 25: 2493-2500.

39. Deuschl G, Schade-Brittinger C, Krack P, Volkmann J, Schäfer H, et al. (2006) A randomized trial of deep-brain stimulation for Parkinson's disease. N Engl J Med 355: 896-908.

40. Arnulf I, Bejjani BP, Garma L, Bonnet AM, Houeto JL, et al. (2000) Improvement of sleep architecture in PD with subthalamic nucleus stimulation. Neurology 55: 1732-1734.

41. Chahine LM, Ahmed A, Sun Z (2011) Effects of STN DBS for Parkinson's disease on restless legs syndrome and other sleep-related measures. Parkinsonism Relat Disord 17: 208-211.

42. Amara AW, Standaert DG, Guthrie S, Cutter G, Watts RL, et al. (2012) Unilateral subthalamic nucleus deep brain stimulation improves sleep quality in Parkinson's disease. Parkinsonism Relat Disord 18: 63-68.

43. Monaca C, Ozsancak C, Jacquesson JM, Poirot I, Blond S, et al. (2004) Effects of bilateral subthalamic stimulation on sleep in Parkinson's disease. J Neurol 251: 214-218.

44. Lyons KE, Pahwa R (2006) Effects of bilateral subthalamic nucleus stimulation on sleep, daytime sleepiness, and early morning dystonia in patients with Parkinson disease. J Neurosurg 104: 502-505.

45. Iranzo A, Valldeoriola F, Santamaraa J, Tolosa E, Rumia J (2002) Sleep symptoms and polysomnographic architecture in advanced Parkinson's disease after chronic bilateral subthalamic stimulation. J Neurol Neurosurg Psychiatry 72: 661-664.

46. Rye DB (1997) Contributions of the pedunculopontine region to normal and altered REM sleep. Sleep 20: 757-788.

47. Kedia S, Moro E, Tagliati M, Lang AE, Kumar R (2004) Emergence of restless legs syndrome during subthalamic stimulation for Parkinson disease. Neurology 63: 2410-2412.

48. Volkmann J, Albanese A, Kulisevsky J, Tornqvist AL, Houeto JL, et al. (2009) Long-term effects of pallidal or subthalamic deep brain stimulation on quality of life in Parkinson's disease. Mov Disord 24: 1154-1161.

49. Rodrigues JP, Walters SE, Watson P, Stell R, Mastaglia FL (2007) Globus pallidus stimulation improves both motor and nonmotor aspects of quality of life in advanced Parkinson's disease. Mov Disord 22: 1866-1870.

50. Arnulf I, Bejjani BP, Garma L, Bonnet AM, Damier P, et al. (2000) Effect of low and high frequency thalamic stimulation on sleep in patients with Parkinson's disease and essential tremor. J Sleep Res 9: 55-62.

51. Lorefält B, Toss G, Granérus AK (2009) Weight loss, body fat mass, and leptin in Parkinson's disease. Mov Disord 24: 885-890.

52. Chen H, Zhang SM, Hernán MA, Willett WC, Ascherio A (2003) Weight loss in Parkinson's disease. Ann Neurol 53: 676-679.

53. Krack P, Batir A, Van Blercom N, Chabardes S, Fraix V, et al. (2003) Five-year follow-up of bilateral stimulation of the subthalamic nucleus in advanced Parkinson's disease. N Engl J Med 349: 1925-1934.

54. Barichella M, Marczewska AM, Mariani C, Landi A, Vairo A, et al. (2003) Body weight gain rate in patients with Parkinson's disease and deep brain stimulation. Mov Disord 18: 1337-1340.

55. Baunez C, Dias C, Cador M, Amalric M (2005) The subthalamic nucleus exerts opposite control on cocaine and 'natural' rewards. Nat Neurosci 8 484-489.

56. Kawada T, Suzuki S (2011) Depressive state, aging, and prevalence of snacking: a preliminary study. Psychogeriatrics 11: 247-248.
57. Marien MR, Colpaert FC, Rosenquist AC (2004) Noradrenergic mechanisms in neurodegenerative diseases: a theory. Brain Res Brain Res Rev 45: 38-78.

58. Sauleau P, Leray E, Rouaud T, Drapier S, Drapier D, et al. (2009) Comparison of weight gain and energy intake after subthalamic versus pallidal stimulation in Parkinson's disease. Mov Disord 24: 2149-2155.

59. Strowd RE, Cartwright MS, Passmore LV, Ellis TL, Tatter SB, et al. (2010) Weight change following deep brain stimulation for movement disorders. J Neurol 257: 1293-1297.

60. Beiske AG, Loge JH, Rønningen A, Svensson E (2009) Pain in Parkinson's disease: Prevalence and characteristics. Pain 141: 173-177.

61. Gerdelat-Mas A, Simonetta-Moreau M, Thalamas C, Ory-Magne F, Slaoui T, et al. (2007) Levodopa raises objective pain threshold in Parkinson's disease: a RIII reflex study. J Neurol Neurosurg Psychiatry 78: 1140-1142.

62. Kim HJ, Jeon BS, Lee JY, Paek SH, Kim DG (2012) The benefit of subthalamic deep brain stimulation for pain in Parkinson disease: a 2year follow-up study. Neurosurgery 70: 18-23.

63. Gierthmühlen J, Arning P, Binder A, Herzog J, Deuschl G, et al. (2010) Influence of deep brain stimulation and levodopa on sensory signs in Parkinson's disease. Mov Disord 25: 1195-1202.

64. Capelle HH, Schrader C, Blahak C, Fogel W, Kinfe TM, et al. (2011) Deep brain stimulation for camptocormia in dystonia and Parkinson's disease. J Neurol 258: 96-103.

65. Loge JH, Kaasa S (1998) Short form 36 (SF-36) health survey: normative data from the general Norwegian population. Scand J Soc Med 26: 250-258.

66. Moreno CB, Hernández-Beltrán N, Munévar D, Gutiérrez-Alvarez AM (2012) Central neuropathic pain in Parkinson's disease. Neurologia 27: 500-503.

67. Dellapina E, Ory-Magne F, Regragui W, Thalamas C, Lazorthes Y, et al (2012) Effect of subthalamic deep brain stimulation on pain in Parkinson's disease. Pain 153: 2267-2273.

68. Loher TJ, Burgunder JM, Weber S, Sommerhalder R, Krauss JK (2002) Effect of chronic pallidal deep brain stimulation on off period dystonia and sensory symptoms in advanced Parkinson's disease. J Neurol Neurosurg Psychiatry 73: 395-399.

69. Honey CR, Stoessl AJ, Tsui JK, Schulzer M, Calne DB (1999) Unilateral pallidotomy for reduction of parkinsonian pain. J Neurosurg 91: 198-201.

70. Tissingh G, Berendse HW, Bergmans P, DeWaard R, Drukarch B, et al. (2001) Loss of olfaction in de novo and treated Parkinson's disease: possible implications for early diagnosis. Mov Disord 16: 41-46.

71. Doty RL, Stern MB, Pfeiffer C, Gollomp SM, Hurtig HI (1992) Bilateral olfactory dysfunction in early stage treated and untreated idiopathic Parkinson's disease. J Neurol Neurosurg Psychiatry 55: 138-142.

72. Guo X, Gao G, Wang X, Li L, Li W, et al. (2008) Effects of bilateral deep brain stimulation of the subthalamic nucleus on olfactory function in Parkinson's disease patients. Stereotact Funct Neurosurg 86: 237-244.

73. Hummel T, Jahnke U, Sommer U, Reichmann H, Müller A (2005) Olfactory function in patients with idiopathic Parkinson's disease: effects of deep brain stimulation in the subthalamic nucleus. J Neural Transm 112: 669-676.

74. Wang J, Eslinger PJ, Smith MB, Yang QX (2005) Functional magnetic resonance imaging study of human olfaction and normal aging. J Gerontol A Biol Sci Med Sci 60: 510-514.

75. Braak H, Del Tredici K, Rüb U, de Vos RA, Jansen Steur EN, et al. (2003) Staging of brain pathology related to sporadic Parkinson's disease. Neurobiol Aging 24: 197-211.

76. Haehner A, Hummel T, Hummel C, Sommer U, Junghanns S, et al. (2007) Olfactory loss may be a first sign of idiopathic Parkinson's disease. Mov Disord 22: 839-842.

77. Sommer U, Hummel T, Cormann K, Mueller A, Frasnelli J, et al. (2004) Detection of presymptomatic Parkinson's disease: combining smell tests, transcranial sonography, and SPECT. Mov Disord 19: 1196-1202. 
Citation: Wang XH, Sperry L, Olichney J, Farias ST, Shahlaie K, et al. (2014) Impact of Deep Brain Stimulation Therapy on Autonomic Disturbances and Related Symptoms of Parkinson's Disease. Brain Disord Ther 4: 150. doi:10.4172/2168-975X.1000150

Page 6 of 6

78. Meissner W, Harnack D, Reese R, Paul G, Reum T, et al. (2003) Highfrequency stimulation of the subthalamic nucleus enhances striatal dopamine release and metabolism in rats. J Neurochem 85: 601-609.
79. Rolls ET, O'Doherty J, Kringelbach ML, Francis S, Bowtell R, et al. (2003) Representations of pleasant and painful touch in the human orbitofrontal and cingulate cortices. Cereb Cortex 13: 308-317. 